\title{
Effects of the acanthocephalan Polymorphus minutus and the microsporidian Dictyocoela duebenum on energy reserves and stress response of cadmium exposed Gammarus fossarum
}

Hui-Yu Chen, Daniel S Grabner, Milen Nachev, Hsiu-Hui Shih, Bernd Sures

Amphipods are commonly parasitized by acanthocephalans and microsporidians and coinfections are found frequently. Both groups of parasites are known to have severe effects on their host. For example, microsporidians can modify host sex ratio and acanthocephalans can manipulate the behavior of the amphipod to promote transmission to the final host. These effects influence host metabolism in general and will also affect the ability of amphipods to cope with additional stressors such as environmental pollution, e.g. by toxic metals. Here we tested the effects of sub-lethal concentrations of cadmium on glycogen and lipid levels, as well as on the 70kDa heat shock protein (hsp70) response of field collected Gammarus fossarum, which were naturally infected with microsporidians and the acanthocephalan Polymorphus minutus. Infected and uninfected $G$. fossarum were exposed to a nominal $\mathrm{Cd}$ concentration of $4 \mu \mathrm{g} / \mathrm{L}$, which resembled measured aqueous $\mathrm{Cd}$ concentration of $2.9 \mu \mathrm{g} / \mathrm{L}$ cadmium in reconstituted water for $7 \mathrm{~d}$ at $15^{\circ} \mathrm{C}$ in parallel to an unexposed control. After exposure gammarids were snap frozen, weighed, sexed and tested for microsporidian infection by PCR. Only individuals containing the microsporidian Dictyocoela duebenum were used for the further biochemical and metal analyses. $P$. minutus infected amphipods were significantly smaller than their uninfected conspecifics. Mortality was insignificantly increased due to cadmium exposure, but not due to parasite infection. Microsporidian infection in combination with cadmium exposure led to increased glycogen levels in female gammarids. An increase of glycogen was also found due to interaction of acanthocephalan and microsporidian infection. Elevated lipid levels were observed in all groups infected with microsporidians, while acanthocephalans had the opposite effect. A positive correlation of lipid and glycogen levels was observed. The general stress response measured in form of hsp70 was significantly increased in microsporidian infected gammarids exposed to cadmium. P. minutus did not affect the stress response of its host. Lipid levels were correlated negatively with hsp70 response, and indicated a possible increased stress susceptibility of individuals with depleted energy reserves. The results of our study clearly demonstrate the importance of parasitic infections, especially of microsporidians, for ecotoxicological research. 
1 Effects of the acanthocephalan Polymorphus minutus and the microsporidian Dictyocoela

2 duebenum on energy reserves and stress response of cadmium exposed Gammarus fossarum

3

4 Hui-Yu Chen ${ }^{1,2 *}$, Daniel S. Grabner ${ }^{1 *}$, Milen Nachev ${ }^{1}$, Shih-Hui Shih ${ }^{2}$, Bernd Sures ${ }^{1,3}$

5 *equal contribution

6

$7{ }^{1}$ Aquatic Ecology and Centre for Water and Environmental Research, University of Duisburg-

8 Essen, Essen, North-Rhine-Westphalia, Germany

$9 \quad{ }^{2}$ Department of Life Science, National Taiwan University, Taipei, Taiwan

$10{ }^{3}$ Department of Zoology, University of Johannesburg, Johannesburg, South Africa

14 Corresponding author:

15 Daniel S. Grabner ${ }^{1}$

16 Universitaetsstr. 5, Essen, North-Rhine-Westphalia, 45141, Germany

17 Email address: daniel.grabner@uni-due.de 
19 Abstract

20 Amphipods are commonly parasitized by acanthocephalans and microsporidians and co-infections

21 are found frequently. Both groups of parasites are known to have severe effects on their host. For

22 example, microsporidians can modify host sex ratio and acanthocephalans can manipulate the

23 behavior of the amphipod to promote transmission to the final host. These effects influence host

24 metabolism in general and will also affect the ability of amphipods to cope with additional stressors

25 such as environmental pollution, e.g. by toxic metals.

26 Here we tested the effects of sub-lethal concentrations of cadmium on glycogen and lipid levels,

27 as well as on the $70 \mathrm{kDa}$ heat shock protein (hsp70) response of field collected Gammarus

28 fossarum, which were naturally infected with microsporidians and the acanthocephalan

29 Polymorphus minutus. Infected and uninfected $G$. fossarum were exposed to a nominal $\mathrm{Cd}$

30 concentration of $4 \mu \mathrm{g} / \mathrm{L}$, which resembled measured aqueous $\mathrm{Cd}$ concentration of $2.9 \mu \mathrm{g} / \mathrm{L}$

31 cadmium in reconstituted water for $7 \mathrm{~d}$ at $15^{\circ} \mathrm{C}$ in parallel to an unexposed control. After exposure

32 gammarids were snap frozen, weighed, sexed and tested for microsporidian infection by PCR.

33 Only individuals containing the microsporidian Dictyocoela duebenum were used for the further

34 biochemical analyses, while infection status of animals used for metal analyses was not tested. $P$.

35 minutus infected amphipods were significantly smaller than their uninfected conspecifics.

36 Mortality was insignificantly increased due to cadmium exposure, but not due to parasite infection.

37 Microsporidian infection in combination with cadmium exposure led to increased glycogen levels

38 in female gammarids. An increase of glycogen was also found due to interaction of

39 acanthocephalan and microsporidian infection. Elevated lipid levels were observed in all groups

40 infected with microsporidians, while acanthocephalans had the opposite effect. A positive

41 correlation of lipid and glycogen levels was observed. The general stress response measured in 
42 form of hsp70 was significantly increased in microsporidian infected gammarids exposed to 43 cadmium. P. minutus did not affect the stress response of its host. Lipid levels were correlated 44 negatively with hsp70 response, and indicated a possible increased stress susceptibility of 45 individuals with depleted energy reserves. The results of our study clearly demonstrate the 46 importance of parasitic infections, especially of microsporidians, for ecotoxicological research. 


\section{Introduction}

Parasites are natural and ubiquitous parts of ecosystems and their role for ecosystem function and stability has been recognized in recent years (Marcogliese, 2005; Hudson, Dobson \& Lafferty, 2006; Kuris et al., 2008). Nevertheless, parasites are often neglected in ecotoxicological research, although results of recent studies showed that they may influence the host response to pollution (Sures, 2004, 2008a,b; Marcogliese \& Giamberini, 2013) and can impact the stress response of their host, especially on the biochemical level (Sures, Lutz \& Kloas, 2006; Sures \& Radszuweit, 2007; Frank et al., 2011, 2013; Gismondi, Cossu-Leguille \& Beisel, 2012a; Gismondi et al., 2012a,b; Filipović Marijić, Vardić Smrzlić \& Raspor, 2013; Grabner, Schertzinger \& Sures, 2014).

Such impacts are particularly relevant when using stress responses on the biochemical level as biomarkers in environmental monitoring programs to indicate the presence of contaminants and to unravel their effects on organisms. As biomarkers are applied under field conditions, their possible modulation by naturally occurring stressors such as parasites has to be evaluated preferably under laboratory conditions as the knowledge about possible interactions between parasites and pollution is still limited (Sures, 2008a; Marcogliese \& Pietrock, 2011).

Amphipods are important elements of aquatic ecosystems due to their widespread distribution, high biomass, and their ecological function as shredders of organic material (Schirling et al., 2005; Platvoet et al., 2006; Navel et al., 2010; Piscart et al., 2011). Because of their sensitivity to contaminants, they are often used as test organism in ecotoxicological studies and particularly in metal toxicity tests (Schill, Görlitz \& Köhler, 2003; Sures \& Radszuweit, 2007; Lebrun et al., 2015). Amphipods are also affected by several parasite groups including acanthocephalans and microsporidians (Taraschewski, 2000; Stentiford et al., 2013). 
72 Acanthocephalans are a group of unique helminth parasites that have an invertebrate intermediate

and a vertebrate final host (Taraschewski, 2000). They often grow to a large size in the body cavity of their amphipod intermediate hosts and can impact them in various ways. For example, they can influence the activity of the host and its predator avoidance behavior (Bauer et al., 2000; MacNeil et al., 2003a,b; Benesh et al., 2008) or affect its reproduction rates (Ward, 1986; Zohar \& Holmes, 1998; Bollache, Gambade \& Cézilly, 2001). Furthermore, acanthocephalans can influence the energy metabolism of the host and its vulnerability to metals (Gismondi, Cossu-Leguille \& Beisel, 2012a,b; Gismondi, Beisel \& Cossu-Leguille, 2012b).

Microsporidians are a diverse group of endoparasitic fungi of invertebrates and vertebrates (Smith, 2009; Stentiford et al., 2013). Their transmission can be horizontal from one individual to another and/or vertical, directly from mother to offspring (Dunn \& Smith, 2001). High prevalences and co-infection cases with up to three microsporidian species underline the importance of these parasites for amphipods (Haine et al., 2004; Grabner, Schertzinger \& Sures, 2014; Grabner et al. 2015). Due to intense proliferation of sporogonic stages microsporidians can modulate the host metabolism or its hormone homeostasis leading to feminization of male individuals (Bandi et al., 2001; MacNeil et al., 2003a; Smith, 2009). Both effects are likely to influence the host response to toxic stressors compared to uninfected individuals. Even under asymptomatic conditions, microsporidians were found to influence the stress response and energy reserves of their amphipod host, when an additional chemical stressor was present (Gismondi et al., 2012a).

Cadmium is released to the environment by various human activities and is frequently found in freshwater ecosystems in concentrations up to several $\mu \mathrm{g} / \mathrm{L}$. It can affect aquatic organisms and whole communities (EPA, 2001). The combination of exposure to metals like cadmium and simultaneous parasite infections can influence the immune response of the host (Cornet et al., 
95 2009) and can increase energy consumption for maintenance of the basic metabolic functions

96 (Gismondi et al., 2012b). Both glycogen and lipids are important energy reserves in animals and

97 their levels can be used as biomarkers for metabolic stress (Plaistow, Troussard \& Cézilly, 2001).

98 Additionally, heat shock proteins (hsp) can be used as general stress markers, suitable to detect

99 effects of parasites and metal exposure in amphipods (Schill, Görlitz \& Köhler, 2003; Frank et al.,

100 2013). The effect of cadmium exposure in combination with infection with the acanthocephalan

101 Polymorphus minutus and microsporidians was already investigated in detail for the amphipod

102 Gammarus roeseli (Gismondi et al., 2012b). Both G. roeseli and G. fossarum are suitable hosts

103 for P. minutus, however it was found that they respond differently (e.g. on biochemical and

104 behavioral level) to infection (Bauer et al., 2000; Helluy, 2013). We assumed that G. fossarum

105 might also react differently to the combination of stressors such as metal pollution and parasite

106 infections. Therefore, the aim of the present study was to investigate the combined effects of

107 parasitism and cadmium pollution on ecotoxicological biomarkers such as energy metabolism

108 (total lipid and glycogen content) and general stress response (hsp70) of G. fossarum. For this

109 purpose, we conducted laboratory exposure experiments with amphipods, which were naturally

110 infected with microsporidians and acanthocephalans.

\section{Material and Methods}

\section{Sampling of gammarids and exposure design}

114 Gammarids were collected by kick-sampling from a small stream (Rumbach) near Mülheim (N51 ${ }^{\circ}$

115 25' 28.628"; E6 ${ }^{\circ}$ 54' 25.553"), NRW, Germany in March 2014. This site is characterized by a

116 mixed population of Gammarus pulex and Gammarus fossarum, and high prevalence of the

117 acanthocephalan Polymorphus minutus in both amphipod species (unpublished results). After 
118 sorting the collected gammarids under a binocular a total of 382 G. fossarum was used for the

119 experiment.

120 The gammarids were grouped by acanthocephalan infection (only amphipods infected with single

121 cystacanths were used) and kept in the laboratory for 2 days at $15^{\circ} \mathrm{C}$ in reconstituted water $(7.36$

$\left.122 \mu \mathrm{M} \mathrm{NaCl}, 231.39 \mu \mathrm{M} \mathrm{KCl}, 117.13 \mu \mathrm{M} \mathrm{NaHCO}_{3}, 707.05 \mu \mathrm{M}, \mathrm{MgSO}_{4} \cdot 7 \mathrm{H}_{2} \mathrm{O}, 303.70 \mu \mathrm{M}\right)$. Alder

123 leaves from the sampling site were used as food source. The exposure experiment was conducted

124 in six 2 L-tanks for control and cadmium-exposed groups, respectively. Each tank contained both

125 acanthocephalan-uninfected $G$. fossarum $(\mathrm{n}=16-17)$ and gammarids infected with P. minutus $(\mathrm{n}$

$126=14-16)$. All animals were kept in reconstituted water and cadmium was added to the exposed

127 groups to achieve a nominal concentration of $4 \mu \mathrm{g} / \mathrm{L}$ (diluted from a $1 \mathrm{~g} / \mathrm{L} \mathrm{Cd}$ standard, $\mathrm{Cd}\left(\mathrm{NO}_{3}\right)_{2}$

128 in $0.5 \mathrm{M} \mathrm{HNO}_{3}$, Bernd $\left.\mathrm{Kraft} \mathrm{GmbH}\right)$. The duration of the exposure was $7 \mathrm{~d}$ at $15^{\circ} \mathrm{C}$ in a climate

129 chamber with 12/12 light/dark-cycle. This exposure time was considered to be long enough, as

130 Gismondi, Cossu-Leguille \& Beisel (2012b) found effects of cadmium on energy reserves of

131 gammarids already after 96h exposure. Experimental tanks were aerated to saturation. No food

132 was provided during the experimental exposure. Water had a temperature of $14.5^{\circ} \mathrm{C}( \pm 0.5)$, a $\mathrm{pH}$

133 of $8.1( \pm 0.1)$ and a conductivity of $1010.1 \mu \mathrm{S} / \mathrm{cm}( \pm 7.8)$ in the control tanks and $14.3^{\circ} \mathrm{C}( \pm 0.5)$,

$134 \mathrm{pH} 8.0( \pm 0.2)$ and $1015.1 \mu \mathrm{S} / \mathrm{cm}( \pm 17.2)$ in the cadmium tanks. Water samples for metal analysis

135 were taken from each tank at different time points: once before cadmium was added and after 5,

$13610,20,30,60,120,240 \mathrm{~min}$, followed by daily sampling until the end of the experiment. A sample

137 of $5 \mathrm{~mL}$ was filtered (cellulose nitrate filter, pore size $0.45 \mu \mathrm{m}$, Sartorius AG), acidified with $5 \mu \mathrm{L}$

$138 \mathrm{HNO}_{3}\left(65 \%\right.$ suprapure, Merck) and stored at $-20^{\circ} \mathrm{C}$ until metal analysis. If present, dead

139 gammarids were removed from the tanks twice daily and were discarded. At the end of the

140 exposure period, gammarids were removed from the aquaria with a sieve, blotted dry and weighed. 
141 Cystacanths were dissected from infected amphipods and stored in separate tubes. All samples

142 were snap frozen individually in $1.5 \mathrm{~mL}$ reaction tubes in liquid nitrogen and stored at $-80^{\circ} \mathrm{C}$.

144 Metal analyses

145 Cadmium concentrations in water samples, gammarids and cystacanths were determined by 146 electrothermal atomic absorption spectrometry (ET-AAS) as described in Sures, Taraschewski \& 147 Haug (1995). Water samples from 2 tanks were pooled resulting in three samples for each group.

148 The acidified water samples were determined without any further pretreatment in duplicate. For 149 tissue analysis, whole gammarids (not tested for microsporidian infection status) or cystacanths 150 were pooled to achieve sample wet weight ranging from 55 to $80 \mathrm{mg}$ for gammarids (2 males and 1512 females with and without $P$. minutus from control and cadmium-treatment) or $11 \mathrm{mg}$ for 152 cystacanths (one pool of 69 for control and 66 for cadmium-treatment). Samples were digested in 153 a mixture of $1.3 \mathrm{~mL}$ nitric acid $\left(65 \% \mathrm{HNO}_{3}\right.$, suprapure, Merck) and $2.5 \mathrm{~mL}$ hydrogen peroxide $154\left(30 \% \mathrm{H}_{2} \mathrm{O}_{2}\right.$, AppliChem) using a microwave digestion procedure described by Zimmermann et al. 155 (2001). To determine the detection limits, blanks were prepared without addition of sample. 156 Cadmium concentrations of samples were calculated by fitting linear regression lines to the points 157 defined by spiked samples and the corresponding integrated peak areas.

\section{Molecular identification of microsporidians}

160 After thawing, the sex of gammarids was determined according to male genital papillae or female 161 oostegites. Acanthocephalan infected individuals were dissected, cystacanths removed and stored 162 at $-20^{\circ} \mathrm{C}$ for metal analysis. Each G. fossarum specimen was homogenized with micropestles in $1630.1 \mathrm{M}$ sodium phosphate buffer with $0.1 \mathrm{M} \mathrm{KCl}$. The buffer volume was adjusted to the threefold 
164 wet weight of every individual (e.g. $60 \mu \mathrm{L}$ of homogenization buffer for $20 \mathrm{mg}$ of wet weight

165

166

167

168

169

170 tissue). Samples were centrifuged at $14.000 \mathrm{x}$ g for $15 \mathrm{~min}$ at $4^{\circ} \mathrm{C}$. The supernatant was used for quantification of total protein concentration and analysis of glycogen, lipid and $70 \mathrm{kDa}$ heat shock protein (hsp70) (see below). The remaining pellet was used for molecular diagnosis of microsporidian infections.

DNA was extracted from pellets with a JETQUICK Tissue DNA spin kit (Genomed) according to manufacturer's instructions. For molecular detection of microsporidian infections, the primers V1 5'-CAC CAG GTT GAT TCT GCC TGA C-3' (Zhu et al., 1993) and Micro_rev 5'-GAG TCA AAT TAA GCC GCA CAA TCC AC-3' (Krebes et al., 2010), amplifying a part of the small subunit ribosomal RNA gene (ss rDNA) of microsporidians, were used. For initial identification of microsporidian species infecting the gammarids, PCR bands of 10 randomly selected samples were gel purified with a JETQUICK PCR Product Purification Spin Kit (Genomed) according to manufacturer's instructions and were sent for sequencing (GATC). All obtained sequences were tested for matches in the GenBank by blast-search (http://blast.ncbi.nlm.nih.gov/Blast.cgi).

According to the obtained sequences, specific primers for each of the three microsporidian species detected were designed (see table 1) to test the remaining positive samples. All PCR reactions contained $4 \mu \mathrm{L}$ of 5x OneTaq Hot Start Buffer (New England Biolabs), $0.2 \mathrm{mM}$ dNTP mix (New England Biolabs), $0.5 \mu \mathrm{M}$ of each primer (MWG Eurofins), 0.5 U OneTaq Hot Start (New England Biolabs) and $1 \mu \mathrm{L}$ template DNA. The mix was topped up to $20 \mu \mathrm{L}$ with PCR grade water. The DNA was amplified by a Labcycler (SensoQuest). PCR conditions for the V1/Micro_rev primers were $94^{\circ} \mathrm{C}$ for $3 \mathrm{~min}, 40$ cycles of $94^{\circ} \mathrm{C}$ for $30 \mathrm{~s}$, annealing at $60^{\circ} \mathrm{C}$ for $35 \mathrm{~s}$, elongation at $68^{\circ} \mathrm{C}$ for $1 \mathrm{~min}$ and a final elongation at $68^{\circ} \mathrm{C}$ for $3 \mathrm{~min}$. The other primers were used under the following conditions: initial denaturation at $94^{\circ} \mathrm{C}$ for $5 \mathrm{~min}, 35$ cycles of $94^{\circ} \mathrm{C}$ for $30 \mathrm{~s}$, annealing at $60^{\circ} \mathrm{C}$ 
187 for $35 \mathrm{~s}$ and elongation at $68^{\circ} \mathrm{C}$ for $40 \mathrm{~s}$ followed by a final elongation of $68^{\circ} \mathrm{C}$ for $3 \mathrm{~min}$. PCR 188 bands were analyzed by conventional agarose gel electrophoresis. Specificity of diagnostic primers

189 was assessed by sequencing of three randomly selected PCR products of each primer pair and 190 comparison to the sequences obtained with the primers V1/Micro_rev.

191

\section{Biochemical analyses}

193 Total protein analysis

194 The amount of total protein in the samples supernatants was measured with a BCA Protein Assay 195 Kit (Pierce) according to manufacturer's instructions. A $10 \mu \mathrm{L}$ aliquot of the supernatant was diluted 1:10 with homogenization buffer and $25 \mu \mathrm{L}$ of the diluted samples were subsequently measured in triplicates in 96-well plates together with a dilution series of a bovine serum albumin standard in a plate reader (Tecan infinite M200).

Glycogen analysis

The pellet obtained after the methanol/chloroform-extraction (see below) was dissolved in $200 \mu \mathrm{L}$ of deionized water. Of this solution, $100 \mu \mathrm{L}$ were transferred into clean $15 \mathrm{~mL}$ culture tubes with in a water bath at $95^{\circ} \mathrm{C}$ for $17 \mathrm{~min}$, and was subsequently cooled on ice. The optical density was measured at $625 \mathrm{~nm}$ in 96-well plates in triplicates. As a reference, a standard of $25-800 \mu \mathrm{g} / \mathrm{mL}$ of glucose was used. Measurements were expressed as $\mu \mathrm{g}$ glycogen $/ \mu \mathrm{g}$ total protein. 
209 To measure total lipid and glycogen content we used the method described by Gismondi et al. 210 (2012a), which was adapted from Plaistow, Troussard \& Cézilly (2001). After homogenization

211 and centrifugation (see above), $10 \mu \mathrm{L}$ of $2 \%$ sodium sulfate $(\mathrm{w} / \mathrm{v})$ and $270 \mu \mathrm{L}$ of

212 chloroform/methanol 1:2(v/v) were added to $20 \mu \mathrm{L}$ of supernatant. After $1 \mathrm{~h}$ incubation on ice,

213 the samples were centrifuged at $3000 \mathrm{x}$ g for $10 \mathrm{~min}$ at $4^{\circ} \mathrm{C}$. The pellet was used for glycogen

214 analysis (see below). For determination of the lipid content, $100 \mu \mathrm{L}$ of the supernatant were

215 transferred to clean reaction tubes. The tubes were incubated overnight at room temperature to

216 evaporate the solvent. Subsequently, $200 \mu \mathrm{L}$ of $95 \%$ sulfuric acid were added and heated for 10

$217 \mathrm{~min}$ at $95^{\circ} \mathrm{C}$ in a water bath. After cooling for $5 \mathrm{~min}, 4.8 \mathrm{~mL}$ of phospho-vanillin reagent were

218 added and the tubes were vortexed until development of a reddish color. After 10 min incubation

219 at room temperature, $300 \mu \mathrm{L}$ of the solution were pipetted into wells of a 96 -well plate and 220 measured within $10 \mathrm{~min}$ at $535 \mathrm{~nm}$ in a plate reader. All samples were measured in triplicate. The 221 content of total lipid was determined from a series of cholesterol standard solutions in 222 concentrations of $100-2000 \mu \mathrm{g} / \mathrm{mL}$. The measurements were expressed in $\mu \mathrm{g} \operatorname{lipid} / \mu \mathrm{g}$ total 223 protein.

\section{Heat shock protein 70 analysis}

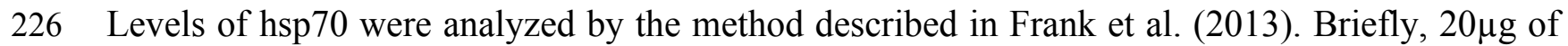
227 proteins were separated by discontinuous SDS-Page, transferred to a nitrocellulose membrane by 228 Western Blot and visualized using monoclonal anti hsp70 antibodies (mouse anti hsp70, antibodies online), a horseradish peroxidase labeled second antibody (goat-anti mouse, DAKO) and detections by 4-chloro-1-naphthol. Gammarids that died during the experiment were excluded

231 from this analysis. To allow inter-gel comparability, a reference sample (fish liver homogenate) 
232 was run on all gels. The hsp70-bands, were scanned and quantified densitometrically with ImageJ

233 (Abràmoff, Magalhães \& Ram, 2004). All sample values were divided by the value of the standard

234 of the respective gel and were expressed as relative hsp70 values.

\section{Statistical analyses}

237 The weight difference of male and female gammarids was tested with the Welch two sample t-test 238 for unequal variances. A possible effect of the treatment on the mortality rate of gammarids was 239 tested with Kruskal-Wallis-test and Dunn's multiple comparison tests. The effects of gammarid 240 sex, microsporidian and acanthocephalan infection and exposure, as well as the influence of 241 parasitism on host size (separately for females and males) was analyzed by linear models and 242 subsequent ANOVA. Due to the variance heterogeneity, the GLS (generalized least squares fit by 243 restricted maximum likelihood, REML) function of the nlme-library (Pinheiro et al., 2014) was 244 used, which allows to correct for unequal variances. Possible correlations of the biochemical 245 parameters were tested with the cor.test-function (Pearson product moment correlation). The 246 statistical analyses were carried out in R v.3.0.1 (R Core Team, 2013) and graphs were created in 247 GraphPad Prism v5.0.

\section{Results}

\section{Prevalence of $\boldsymbol{P}$. minutus}

After the exposure experiment, a total of 299 living gammarids was recovered. Among these, 88 of the 160 males $(55.0 \%)$ and 55 of the 139 females $(39.6 \%)$ were infected with $P$. minutus. The overall prevalence of this acanthocephalan in the test population was $48 \%$ (supplemental table S1). 


\section{Metal analyses}

256 Cadmium levels in control water were lower than $0.1 \mu \mathrm{g} / \mathrm{L}$ during the experiment. In cadmium-

257

258

259

260

261

262

263

264

265

266

267

268

269

270

271

272

273

274

275

276

exposed groups, concentrations were declining gradually after addition of stock-solution and reached a stable concentration of $2.89 \mu \mathrm{g} / \mathrm{L}$ on average after about $5 \mathrm{~h}$ (figure 1). The tissue concentrations of uninfected and P. minutus-infected control gammarids were below $0.2 \mu \mathrm{g} / \mathrm{g}$. Cadmium-exposed female gammarids had almost ten-fold higher cadmium concentrations, and the respective males had close to eight-fold higher concentrations than control animals. Cadmiumexposed female gammarids accumulated cadmium to a higher extent than male gammarids (1.5 and 1.1 times higher for uninfected and P. minutus-infected group respectively). The cadmium concentrations determined in P. minutus cystacanths from cadmium-exposed gammarids were approximately four times higher than those of cystacanths from control gammarids (figure 2).

\section{Microsporidian infections in gammarids}

After the exposure experiment, 212 G. fossarum individuals were tested for microsporidian infections. Gammarids used for metal analyses could not be tested by PCR, so their microsporidian-infection status remains unclear. By sequencing, three different microsporidian isolates were obtained: (1) 1300 bp (GenBank accession no. KR871381), 99\% similarity to Microsporidium sp. 505 (FN434085); (2) 433 bp (KR871382), undefined Microsporidium sp. MH with 93\% identity to Cystosporogenes sp. (GQ379704) and (3) 680 bp (KR871380), 98\% similarity to Dictyocoela duebenum (JQ673483). Due to the sequence divergence between previous isolates of $D$. duebenum and our Dictyocoela species, we can only make a putative identification here. The prevalences of the different microsporidians in the population are shown 
277 in supplemental figure S1. Individuals infected only with $D$. duebenum were considered in

278 biochemical analyses, as this species was the most abundant.

279 In total, $65 \%$ of the gammarids were infected with either one or several microsporidian species

280 simultaneously. The prevalence of microsporidians was higher in males $(77.7 \%)$ than in females

281 (48.4\%). Infections with $D$. duebenum only were recorded in $70.8 \%$ of females and $62.3 \%$ of

282 males. In total $26.4 \%$ of gammarids were infected simultaneously with microsporidians and $P$.

283 minutus cystacanths, with a higher percentage of males $(38.0 \%)$ compared to females $(11.0 \%)$

284 (supplemental table S1).

285

286

Effects of infection on gammarid weight

287 The mean weight of females $(19.96 \mathrm{mg})$ and males $(25.63 \mathrm{mg})$ differed significantly (Welch two

288 sample $\mathrm{t}$-test; $\mathrm{t}=-5.18, \mathrm{p}<0.001$; (figure 3). Additionally, acanthocephalan infected gammarids

289 had a significantly lower weight than their uninfected conspecifics (females: infected $18.84 \mathrm{mg}$ vs

$29020.47 \mathrm{mg}$ for uninfected gammarids, $\mathrm{F}=5.90, \mathrm{p}<0.05$; males: infected $22.94 \mathrm{mg}$ vs uninfected

$29128.70 \mathrm{mg}$ for uninfected gammarids, $\mathrm{F}=11.07, \mathrm{p}<0.01)$. In contrast, microsporidian infection

292 was not correlated with the weight of gammarids (females: $F=0.01, p=0.92$; males: $F=0.27, p$

$293=0.61$; figure 3).

294

295 Mortality rate of gammarids

296 In the control groups, mortality was slightly higher in the P. minutus-infected group (20.0\%)

297 compared to the group of uninfected gammarids $(17.0 \%$, see figure 4$)$. The mortality in cadmium-

298 exposed groups was overall higher, with a slightly higher death rate $(27.0 \%)$ in uninfected

299 gammarids compared to P. minutus-infected ones (26.1\%). On average, the mortality in the control 
300 group was $18.4 \%$, whereas $26.6 \%$ of the cadmium exposed gammarids died. No significant

301 differences between the groups were detected (figure 4).

302

303 Biochemical analyses

304 Uninfected, P. minutus infected, D. duebenum infected and gammarids infected with both parasites

305 were used for further analyses. At all a total of 54 female and 60 male gammarids was available

306 for the biochemical analysis. The output of the GLS model is shown in supplemental table S2.

Glycogen

309 Overall, cadmium exposure decreased glycogen levels, but the analyses indicated a significant

310 increasing effect of cadmium-exposure on glycogen levels in microsporidian infected female

311 gammarids. A similar increase was found in unexposed males (table 2, figure 5). Also, a significant

312 interaction was present for microsporidian and acanthocephalan infection showing increased

313 glycogen levels (table 2, figure 5, supplemental table S2). According to the GLS, increased

314 glycogen levels are also present in females compared to males, independent of exposure and

315 parasites (table 2, figure 5, supplemental table S2).

316

317 Lipids

318 Similar to glycogen, total lipids were significantly decreased by cadmium exposure, but this effect

319 was modulated by parasite infection. Also, the total lipid content was highly dependent of host

320 sex, with lower concentrations in males than in females (figure 6, table 2). The acanthocephalan

321 infection significantly decreased the total lipid level in all groups, except for cadmium-exposed

322 males, which is reflected by the significant interactive effect of host sex and $P$. minutus infection 
323 (table 2, supplemental table S2). Microsporidians caused a significant increase of total lipids

324 especially in females. This increase was less pronounced in cadmium exposed individuals (figure 3256 , table 2).

326

327 hsp70 levels

328 For 3 samples (3 exposed, uninfected females), no hsp70 values were obtained (no visible band) 329 and 2 ( 1 exposed and 1 unexposed, uninfected female) dropped out as outliers ( $>3$ fold above 330 group average). The combination of cadmium exposure and microsporidian infection had a 331 significant increasing effect on hsp70 levels, while microsporidians alone had no effect on hsp70 332 (table 2, figure 7, supplemental table S2). Cadmium exposure also increased the hsp70 level in the 333 other infected and uninfected groups. Infection with $P$. minutus did not have a significant influence 334 on the hsp70 levels (table 2, supplemental table S2). Nevertheless, a slight increase in the hsp70 335 level can be observe for unexposed and acanthocephalan infected females according to figure 7.

337 Correlations

338 Correlation analyses revealed significant negative correlation between lipids and hsp70 $(\mathrm{n}=109$, $339 \mathrm{p}<0.001, \rho=-0.32)$, and weak positive correlations between lipid and glycogen $(\mathrm{n}=109, \mathrm{p}<$ $3400.01, \rho=0.28)$. No significant correlation was found for hsp70 and glycogen.

\section{Discussion}

343 The present study provides data on combined and single effects of parasite infections 344 (Acanthocephala and Microsporidia) and cadmium-exposure on mortality, energy reserves of the 345 gammarid host and its stress response quantified by the hsp70 levels. Three microsporidian isolates 
346 were detected in the naturally infected Gammarus population, including one novel isolate. For the

347 biochemical analyses, only infections with $D$. duebenum (species assignment putative) were

348 considered. The latter parasite was found frequently in different amphipod species and is

349 characterized by a vertical mode of transmission and is known to feminize the host population by

350 sexual conversion (Terry et al., 2004). Virulence of this microsporidian is considered to be low,

351 but sub-lethal effects on the host were not well studied until now. Surprisingly, we did not observe

352 a female bias among Dictyocoela-infected G. fossarum in the present study. Nevertheless, this

353 parasite might influence host metabolism in the attempt to elicit feminization. This might have

354 influenced the outcome of our analyses, but this effect remains speculative here.

355 According to our results, the weight of $G$. fossarum was lower in acanthocephalan infected male

356 and female hosts, while microsporidian infection showed no significant effect. This indicates that

357 either smaller individuals were more likely to be infected with $P$. minutus, or that this parasite

358 influences host feeding behavior and its growth rates (Agatz \& Brown, 2014).

359 The cadmium concentration used in the present study was about factor 100 below the $96 \mathrm{~h}$ LC50

360 values reported for G. fossarum in previous studies (Alonso, De Lange \& Peeters, 2010; Boets et

361 al., 2012) therefore no severe mortality was expected. Nevertheless, besides a baseline mortality

362 of about $20 \%$ we observed an additional mortality of $6 \%-10 \%$ in the cadmium exposed groups.

363 Our results showed also no negative effect of $P$. minutus on host mortality, while mortality was

364 slightly higher (although not significant) in cadmium exposed G. fossarum. Gismondi, Cossu-

365 Leguille \& Beisel (2012b) found an increased cadmium tolerance in male G. roeseli infected with

366 P. minutus, while infected females became more susceptible to combined stressors. Such sex

367 dependent difference in susceptibility to cadmium was also reported for G. fossarum, where

368 females were less tolerant to the exposure than males (Schill, Görlitz \& Köhler, 2003). 
369 The energy reserves of $G$. fossarum were influenced by both cadmium-exposure and parasite 370 infection. Glycogen content increased in D. duebenum infected individuals with a heterogeneous 371 effect of host sex. Gismondi et al. (2012a) also reported an increase in glycogen in Dictyocoela372 infected G. roeseli, but a decrease after cadmium exposure. In another study (Gismondi et al., 373 2012b), an increase of glycogen levels was detected depending on both microsporidian infection 374 and cadmium exposure, similar to the present study. Only females infected with microsporidians 375 were used in the latter study, therefore effects of host sex cannot be compared. In our study, slightly 376 elevated glycogen levels in acanthocephalan infected female amphipods were found. This effect due to acanthocephalan infection was also described previously (Plaistow, Troussard \& Cézilly, 2001), but the sex effect was dependent on the season when amphipods were sampled (Gismondi, Beisel \& Cossu-Leguille, 2012b). An increase in glycogen levels in acanthocephalan infected individuals seems to be a common phenomenon. It might be explained by the increased uptake of nutrients due to extended energy requirements of the infected host or due to a quick mobilization of energy storage during the growth phase of the parasite (Sparkes, Keogh \& Pary, 1996). In contrast, the need for detoxification of pollutants might cause an increased metabolic activity that depletes glycogen storages. Furthermore, presence of both acanthocephalan and microsporidian infection caused significantly increased glycogen concentrations. This is in contrast to Gismondi et al. (2012b) who found depleted glycogen levels in $G$. roeseli infected with microsporidians and acanthocephalans at the same time.

Similar to glycogen, an increase of total lipids was observed in males and females of G. fossarum infected with the microsporidium $D$. duebenum, while cadmium-exposure had a decreasing effect. Previously, a similar increase in lipid levels due to microsporidians compared to the uninfected control was found for $G$. roeseli exposed to a nominal cadmium concentration of $8 \mu \mathrm{g} / \mathrm{L}$ (Gismondi 
392 et al., 2012b), but not at $2 \mu \mathrm{g} / \mathrm{L}$ or in unexposed control groups. Therefore, the nominal cadmium

393 concentration of $4 \mu \mathrm{g} / \mathrm{L}(2.9 \mu \mathrm{g} / \mathrm{L}$ measured $)$ used in the present study might be the threshold that

394 caused an effect in the exposed amphipods. Interestingly, the opposite was observed in G. roeseli

395 infected with $P$. minutus, where decreased lipid levels were reported after exposure to $2 \mu \mathrm{g} / \mathrm{L}$

396 cadmium concentration, but not to $8 \mu \mathrm{g} / \mathrm{L}$ (Gismondi et al., 2012b; Gismondi, Beisel \& Cossu-

397 Leguille, 2012b). In the present study, the acanthocephalan infected group showed slightly

398 decreased lipid levels, which was most pronounced in females independent of exposure condition.

399 Similar to glycogen storage, the parasite might drive host metabolism to utilize the lipid storage

400 depending on its own requirements. The variable results observed for the lipid content in different

401 studies could be due to seasonal variation in reserves substances like lipids or glycogen (Gismondi,

402 Beisel \& Cossu-Leguille, 2012a,b). Additionally, they could indicate different response patterns

403 to cadmium and parasites by the two host species G. fossarum and G. roeseli.

404 To summarize, the response of G. fossarum and G. roeseli to cadmium and parasites on the level 405 of energy reserves is essentially similar although slight species-specific differences might be present. Due to the positive correlation between glycogen and lipid levels in the present study, it

407 can be assumed that they respond similarly to parasite infection. Especially lipids represent nutrient reserves to prevent starvation and to provide energy for reproduction; therefore changes of lipid levels represent long-term physiological effects in the host that might impair its survival and that can have an effect on the population development under stressed conditions (Cargill et

411 al., 1985).

412 Increased levels of hsp70 indicate a general stress response (protein damage) of an organism, e.g.

413 to chemicals or effects of parasite infections (Frank et al., 2013). In the present study, a clear stress-

414 effect was detected in microsporidian-infected G. fossarum exposed to cadmium, while no 
415 significant effect of infection with P. minutus was observed. A similar increase of hsp70 due to

416 multiple microsporidian infection was already observed previously in G. pulex (Grabner,

417 Schertzinger \& Sures, 2014). In the study of Gismondi et al. (2012b), malondialdehyde as a marker

418 for lipid oxidation and therefore cellular damage, similar to hsp70, was increased in G. roeseli

419 after cadmium-exposure. This effect was even more pronounced, if the amphipods were

420 additionally infected with microsporidians, acanthocephalans or with both together. These findings

421 provide evidence for the idea that intracellular replication of microsporidians causes a

422 destabilization of cell metabolism leading to protein damage (measured by hsp70 or

423 malondialdehyde), if additional stressors (here cadmium) are present.

424 An irregular pattern of the hsp70 response was observed in previous studies, caused by the 425 combined effect of $P$. minutus infection and thermal or chemical stress on gammarids. No 426 increased levels of hsp70 were detected in infected G. roeseli after exposure to either heat or 427 palladium (Sures \& Radszuweit, 2007). Similar results were reported for G. fossarum infected 428 with P. minutus, comparing uninfected and cadmium-exposed animals (Frank et al., 2013). Such response patterns were not observed in the present study, as $P$. minutus induced no considerable 430 hsp70 response. Again differences between the amphipod species might provide an explanation. 431 Peschke et al. (2014) found remarkable differences in the hsp70 response of uninfected G. pulex 432 and G. roeseli populations from sampling sites with different pollutant burdens. The response of 433 hsp70 in G. pulex showed variations, while no effect was seen in G. roeseli from the same sites. 434 Similar differences might exist between G. roeseli and G. fossarum. Nevertheless the different 435 findings of Frank et al. (2013) and the present study, both using G. fossarum, remain to be 436 elucidated. Interestingly, a negative correlation was found between hsp70 and lipids, which 437 indicates that individuals with depleted energy reserves are more prone to stress effects. 
438 In the present study cadmium-concentrations were slightly lower in males of G. fossarum than in

439 females. No significant differences were detected if $P$. minutus-infected and uninfected amphipods

440 were compared. In contrast, significant lower cadmium-concentrations were detected in G. roeseli

441 (Gismondi, Cossu-Leguille \& Beisel, 2012b) or G. fossarum (Frank et al., 2013) infected with $P$.

442 minutus although both studies used similar sublethal concentrations of cadmium. This might be

443 explained by the low number of individuals analyzed in the present study that did not allow

444 detection of such differences. Cystacanths showed a lower cadmium accumulation potential

445 compared to host tissues, but this finding is based only on one replicate. Similar findings were

446 described before for other host-parasite systems, e.g. Asellus aquaticus - Acanthocephalus lucii

447 (Sures \& Taraschewski, 1995), G. pulex - Pomphorhynchus laevis (Siddall \& Sures, 1998) as well

448 as for G. fossarum - P. minutus (Frank et al., 2013).

449

450 Conclusion

451 Microsporidian infections were found to influence the metabolism and the stress response of $G$.

452 fossarum exposed to sub-lethal cadmium concentrations. In contrast, the effect of $P$. minutus

453 cystacanths on energy reserves and stress response of the host was less pronounced. Our data

454 together with data from previous studies indicates slight species dependent differences in the

455 response to multiple stressors (e.g. parasitism and metal pollution). Furthermore, we highly

456 recommend that parasitism should be taken into account in future ecotoxicological surveys, as

457 various aquatic organisms are commonly infected and monitoring data could be misinterpreted if 458 their infection status is not considered.

459

460 Acknowledgements 
461 We thank Stephen Short and another anonymous reviewer for the helpful and constructive review

462 that helped to improve the manuscript.

463

464 References

465

466

467

468

469

470

471

472

473

474

475

Abràmoff MD, Magalhães PJ, Ram SJ. 2004. Image Processing with ImageJ. Biophotonics International 11:36-42.

Agatz A, Brown CD. 2014. Variability in feeding of Gammarus pulex: moving towards a more standardised feeding assay. Environmental Sciences Europe 26:15.

Alonso Á, De Lange HJ, Peeters ETHM. 2010. Contrasting sensitivities to toxicants of the freshwater amphipods Gammarus pulex and G. fossarum. Ecotoxicology 19:133-140.

Bandi C, Dunn A, Hurst G, Rigaud T. 2001. Inherited microorganisms, sex-specific virulence and reproductive parasitism. Trends in Parasitology 17:88-94.

Bauer A, Trouve S, Gregoire A, Bollache L, Cezilly F. 2000. Differential influence of Pomphorhynchus laevis (Acanthocephala) on the behaviour of native and invader gammarid species. International Journal for Parasitology 30:1453-1457.

Benesh DP, Kitchen J, Pulkkinen K, Hakala I, Valtonen ET. 2008. The effect of Echinorhynchus borealis (Acanthocephala) infection on the anti-predator behavior of a benthic amphipod. The Journal of Parasitology 94:542-5. 
479 Boets P, Lock K, Goethals PLM, Janssen CR, De Schamphelaere KAC. 2012. A comparison of 480 the short-term toxicity of cadmium to indigenous and alien gammarid species. $481 \quad$ Ecotoxicology 21:1135-44.

482 Bollache L, Gambade G, Cézilly F. 2001. The effects of two acanthocephalan parasites, Pomphorhynchus laevis and Polymorphus minutus, on pairing success in male Gammarus pulex (Crustacea: Amphipoda). Behavioral Ecology and Sociobiology 49:296-303.

Cargill AS, Cummis KW, Hanson BJ, Lowry RR. 1985. The role of lipids as feeding stimulants for shredding aquatic insects. Freshwater Biology 15:455-464.

Cornet S, Franceschi N, Bauer A, Rigaud T, Moret Y. 2009. Immune depression induced by acanthocephalan parasites in their intermediate crustacean host: Consequences for the risk of super-infection and links with host behavioural manipulation. International Journal for Parasitology 39:221-229.

Dunn A, Smith J. 2001. Microsporidian life cycles and diversity: the relationship between virulence and transmission. Microbes and Infection / Institut Pasteur 3:381-8.

EPA. 2001. Update of ambient water quality criteria for cadmium. U.S. Environmental Protection Agency, Office of Water, report 822-R-01-001.

Filipović Marijić V, Vardić Smrzlić I, Raspor B. 2013. Effect of acanthocephalan infection on metal, total protein and metallothionein concentrations in European chub from a Sava River section with low metal contamination. The Science of the Total Environment 463-464:77280. 
499 Frank SN, Faust S, Kalbe M, Trubiroha A, Kloas W, Sures B. 2011. Fish hepatic glutathione-S500 transferase activity is affected by the cestode parasites Schistocephalus solidus and Ligula $501 \quad$ intestinalis: evidence from field and laboratory studies. Parasitology 138:939-944.

502 Frank SN, Godehardt S, Nachev M, Trubiroha A, Kloas W, Sures B. 2013. Influence of the cestode Ligula intestinalis and the acanthocephalan Polymorphus minutus on levels of heat shock proteins (HSP70) and metallothioneins in their fish and crustacean intermediate hosts.

Gismondi E, Rigaud T, Beisel J-N, Cossu-Leguille C. 2012a. Microsporidia parasites disrupt the responses to cadmium exposure in a gammarid. Environmental Pollution 160:17-23.

508 Gismondi E, Rigaud T, Beisel J-N, Cossu-Leguille C. 2012b. Effect of multiple parasitic 509 infections on the tolerance to pollutant contamination. PloS one 7:e41950.

510 Gismondi E, Beisel JN, Cossu-Leguille C. 2012a. Influence of gender and season on reduced 511 glutathione concentration and energy reserves of Gammarus roeseli. Environmental $512 \quad$ Research 118:47-52.

Gismondi E, Beisel J-N, Cossu-Leguille C. 2012b. Polymorphus minutus affects antitoxic responses of Gammarus roeseli exposed to cadmium. PloSone 7:e41475.

515 Gismondi E, Cossu-Leguille C, Beisel J-N. 2012a. Does the acanthocephalan parasite 516 Polymorphus minutus modify the energy reserves and antitoxic defences of its intermediate 517 host Gammarus roeseli? Parasitology 139:1054-1061. 
518 Gismondi E, Cossu-Leguille C, Beisel J-N. 2012b. Acanthocephalan parasites: help or burden in 519 gammarid amphipods exposed to cadmium? Ecotoxicology 21:1188-93.

520

521

522

523

524

525

526

527

528

529

530

531

532

533
Grabner DS, Schertzinger G, Sures B. 2014. Effect of multiple microsporidian infections and temperature stress on the heat shock protein 70 (hsp70) response of the amphipod Gammarus pulex. Parasites \& Vectors 7:170.

Grabner DS, Weigand AM, Leese F, Winking C, Hering D, Tollrian R, Sures B. 2015. Invaders, natives and their enemies: distribution patterns of amphipods and their microsporidian parasites in the Ruhr Metropolis, Germany. Parasites \& Vectors 8: 419.

Haine ER, Brondani E, Hume KD, Perrot-Minnot M-J, Gaillard M, Rigaud T. 2004. Coexistence of three microsporidia parasites in populations of the freshwater amphipod Gammarus roeseli: evidence for vertical transmission and positive effect on reproduction. International Journal for Parasitology 34:1137-46.

Helluy S. 2013. Parasite-induced alterations of sensorimotor pathways in gammarids: collateral damage of neuroinflammation? The Journal of Experimental Biology 216:67-77.

Hudson PJ, Dobson AP, Lafferty KD. 2006. Is a healthy ecosystem one that is rich in parasites? Trends in Ecology \& Evolution 21:381-5.

Krebes L, Blank M, Frankowski J, Bastrop R. 2010. Molecular characterisation of the Microsporidia of the amphipod Gammarus duebeni across its natural range revealed hidden diversity, wide-ranging prevalence and potential for co-evolution. Infection, Genetics and 

Diseases 10:1027-38.

Kuris AM, Hechinger RF, Shaw JC, Whitney KL, Aguirre-Macedo L, Boch CA, Dobson AP, Dunham EJ, Fredensborg BL, Huspeni TC, Lorda J, Mababa L, Mancini FT, Mora AB, Pickering M, Talhouk NL, Torchin ME, Lafferty KD. 2008. Ecosystem energetic implications of parasite and free-living biomass in three estuaries. Nature 454:515-8.

Lebrun JD, Geffard O, Urien N, François A, Uher E, Fechner LC. 2015. Seasonal variability and inter-species comparison of metal bioaccumulation in caged gammarids under urban diffuse contamination gradient: Implications for biomonitoring investigations. Science of the Total Environment 511:501-508.

MacNeil C, Dick JTA, Hatcher MJ, Dunn AM. 2003a. Differential drift and parasitism in invading and native Gammarus spp. (Crustacea : Amphipoda). Ecography 26:467-473.

MacNeil C, Fielding N, Hume K, Dick JTA, Elwood RW, Hatcher MJ, Dunn AM. 2003 b. Parasite altered micro-distribution of Gammarus pulex (Crustacea: Amphipoda). International Journal for Parasitology 33:57-64.

Marcogliese DJ. 2005. Parasites of the superorganism: are they indicators of ecosystem health? International Journal for Parasitology 35:705-16.

Marcogliese DJ, Giamberini L. 2013. Parasites and Ecotoxicology: Fish and Amphibians. In: Férard J-F, Blaise C eds. Encyclopedia of Aquatic Ecotoxicology. Dordrecht: Springer Netherlands, 815-826. 
557 Marcogliese DJ, Pietrock M. 2011. Combined effects of parasites and contaminants on animal

558 health: Parasites do matter. Trends in Parasitology 27:123-130.

559 Navel S, Mermillod-Blondin F, Montuelle B, Chauvet E, Simon L, Piscart C, Marmonier P.

560 2010. Interactions between fauna and sediment control the breakdown of plant matter in

$561 \quad$ river sediments. Freshwater Biology 55:753-766.

562 Peschke K, Geburzi J, Köhler HR, Wurm K, Triebskorn R. 2014. Invertebrates as indicators for

563 chemical stress in sewage-influenced stream systems: Toxic and endocrine effects in

564 gammarids and reactions at the community level in two tributaries of Lake Constance,

565 Schussen and Argen. Ecotoxicology and Environmental Safety 106:115-125.

566 Pinheiro J, Bates D, DebRoy S, Sakar D, Team RC. 2014. nlme: Linear and nonlinear mixed

567 effect models. R package version 3.1-117; http://CRAN.R-project.org/package=nlme.

568 Piscart C, Mermillod-Blondin F, Maazouzi C, Merigoux S, Marmonier P. 2011. Potential impact

569 of invasive amphipods on leaf litter recycling in aquatic ecosystems. Biological Invasions

$570 \quad 13: 2861-2868$.

571 Plaistow SJ, Troussard JP, Cézilly F. 2001. The effect of the acanthocephalan parasite

572 Pomphorhynchus laevis on the lipid and glycogen content of its intermediate host

573 Gammarus pulex. International Journal for Parasitology 31:346-51.

574 Platvoet D, Dick JTA, Konijnendijk N, van der Velde G. 2006. Feeding on micro-algae in the

575 invasive Ponto-Caspian amphipod Dikerogammarus villosus (Sowinsky, 1894). Aquatic

$576 \quad$ Ecology 40:237-245. 
577 Schill RO, Görlitz H, Köhler H-R. 2003. Laboratory simulation of a mining accident: acute

578 toxicity, hsc/hsp70 response, and recovery from stress in Gammarus fossarum (Crustacea,

579 Amphipoda) exposed to a pulse of cadmium. Biometals 16:391-401.

580 Schirling M, Jungmann D, Ladewig V, Nagel R, Triebskorn R, Köhler H-R. 2005. Endocrine

581 effects in Gammarus fossarum (Amphipoda): influence of wastewater effluents, temporal

582 variability, and spatial aspects on natural populations. Archives of Environmental

$583 \quad$ Contamination and Toxicology 49:53-61.

584 Siddall R, Sures B. 1998. Uptake of lead by Pomphorhynchus laevis cystacanths in Gammarus

585 pulex and immature worms in chub (Leuciscus cephalus). Parasitology Research 84:573-7.

586 Smith JE. 2009. The ecology and evolution of microsporidian parasites. Parasitology 136:1901$587 \quad 14$.

588 Sparkes TC, Keogh DP, Pary RA. 1996. Energetic costs of mate guarding behavior in male 589 stream-dwelling isopods. Oecologia 106:166-171.

590 Stentiford GD, Feist SW, Stone DM, Bateman KS, Dunn AM. 2013. Microsporidia: diverse, 591 dynamic, and emergent pathogens in aquatic systems. Trends in Parasitology 29:567-78.

592 Sures B. 2004. Environmental parasitology: Relevancy of parasites in monitoring environmental 593 pollution. Trends in Parasitology 20:170-177.

594 Sures B. 2008a. Environmental parasitology. Interactions between parasites and pollutants in the 595 aquatic environment. Parasite 15:434-438. 
596 Sures B. 2008b. Host-parasite interactions in polluted environments. Journal of Fish Biology

597 73:2133-2142.

598

599

600

601

602

603

604

605

606

607

608

609

610

611

612

613

614

Sures B, Lutz I, Kloas W. 2006. Effects of infection with Anguillicola crassus and simultaneous exposure with Cd and 3,3',4,4',5-pentachlorobiphenyl (PCB 126) on the levels of cortisol and glucose in European eel (Anguilla anguilla). Parasitology 132:281-8.

Sures B, Radszuweit H. 2007. Pollution-induced heat shock protein expression in the amphipod Gammarus roeseli is affected by larvae of Polymorphus minutus (Acanthocephala). Journal of Helminthology 81:191-7.

Sures B, Taraschewski H. 1995. Cadmium concentrations in two adult acanthocephalans, Pomphorhynchus laevis and Acanthocephalus lucii, as compared with their fish hosts and cadmium and lead levels in larvae of $A$. lucii as compared with their crustacean host. Parasitology Research 81:494-497.

Sures B, Taraschewski H, Haug C. 1995. Determination of trace metals $(\mathrm{Cd}, \mathrm{Pb})$ in fish by electrothermal atomic absorption spectrometry after microwave digestion. Analytica Chimica Acta 311:135-139.

Taraschewski H. 2000. Host-parasite interactions in acanthocephala: a morphological approach. Advances in Parasitology 46:1-179.

R Core Team. 2013. A language and environment for statistical computing. R Foundation for Statistical Computing; http://www.R-project.org. 
615 Terry RS, Smith JE, Sharpe RG, Rigaud T, Littlewood DTJ, Ironside JE, Rollinson D, Bouchon

616 D, MacNeil C, Dick JTA, Dunn AM. 2004. Widespread vertical transmission and

617 associated host sex-ratio distortion within the eukaryotic phylum Microspora. Proceedings.

618 Biological sciences / The Royal Society 271:1783-9.

619 Ward PI. 1986. A comparative field study of the breeding behaviour of a stream and a pond 620 population of Gammarus pulex (Amphipoda). Oikos 46:29-36.

621

622

623

624

625

626

627

628

629

630

631

632

633

634

Zhu X, Wittner M, Tanowitz HB, Kotler D, Cali A, Weiss LM. 1993. Small subunit rRNA sequence of Enterocytozoon bieneusi and its potential diagnostic role with use of the polymerase chain reaction. The Journal of Infectious Diseases 168:1570-5.

Zimmermann S, Menzel CM, Berner Z, Eckhardt J-D, Stüben D, Alt F, Messerschmidt J, Taraschewski H, Sures B. 2001. Trace analysis of platinum in biological samples: a comparison between sector field ICP-MS and adsorptive cathodic stripping voltammetry following different digestion procedures. Analytica Chimica Acta 439:203-209.

Zohar S, Holmes JC. 1998. Pairing success of male Gammarus lacustris infected by two acanthocephalans: a comparative study. Behavioral Ecology 9:206-211. 
Table $\mathbf{1}$ (on next page)

Primers 
Table 2. Specific primers used to detect microsporidians.

\begin{tabular}{llcc}
\hline Primer & Sequence $\left(5^{\prime}-3^{\prime}\right)$ & $\begin{array}{l}\text { Amplicon } \\
\text { length }\end{array}$ & Source \\
\hline Mspec 505 & $\begin{array}{l}\text { F: CAT CAA CTA ACT TTG GGA AAC TAA G } \\
\text { R: TGG CCT CCC ACA CAT TCC GAG TG }\end{array}$ & $1300 \mathrm{bp}$ & $\begin{array}{l}\text { Grabner et } \\
\text { al., 2014 }\end{array}$ \\
Micro MH & $\begin{array}{l}\text { F: GTA GAA CTG CGA TGA TTT AGT CTG } \\
\text { R: GCT ATA CCA TGT TCC CCA TTG }\end{array}$ & $433 \mathrm{bp}$ & this study \\
Dict & $\begin{array}{l}\text { F: GGG CGA TTT ATT TGT TCT CCT GT } \\
\text { R: TGA TTT CTC TTC CGC AAT ACC AAA TC }\end{array}$ & $680 \mathrm{bp}$ & this study \\
\hline
\end{tabular}

1 


\title{
Table 2 (on next page)
}

\author{
Analysis
}


Table 4. Results of the ANOVA of the different groups on biochemical parameters

\begin{tabular}{|c|c|c|c|c|c|c|c|c|c|c|c|c|}
\hline \multirow[b]{2}{*}{ Group } & \multicolumn{4}{|c|}{ Glycogen } & \multicolumn{4}{|c|}{ Lipid } & \multicolumn{4}{|c|}{ hsp70 } \\
\hline & DF & F-value & $\mathrm{p}$-value & & DF & F-value & p-value & & DF & F-value & $\mathrm{p}$-value & \\
\hline (Intercept) & 1 & 10475360,20 & 0,000 & & 1 & 20852,74 & 0,000 & & 1 & 772,39 & 0,000 & \\
\hline $\operatorname{sex}$ & 1 & 52,96 & 0,000 & $* * *$ & 1 & 82,41 & 0,000 & $* * *$ & 1 & 2,63 & 0,108 & \\
\hline expo & 1 & 19,58 & 0,000 & $* * *$ & 1 & 6,30 & 0,014 & $*$ & 1 & 13,40 & 0,000 & $* * *$ \\
\hline micro & 1 & 39,65 & 0,000 & $* * *$ & 1 & 23,05 & 0,000 & $* * *$ & 1 & 2,18 & 0,143 & \\
\hline acantho & 1 & 0,39 & 0,535 & & 1 & 10,31 & 0,002 & $* *$ & 1 & 0,98 & 0,325 & \\
\hline sex:expo & 1 & 0,09 & 0,768 & & 1 & 0,00 & 0,986 & & 1 & 6,78 & 0,011 & $*$ \\
\hline sex:micro & 1 & 0,00 & 0,996 & & 1 & 4,14 & 0,045 & $*$ & 1 & 0,01 & 0,938 & \\
\hline expo:micro & 1 & 5,90 & 0,017 & $*$ & 1 & 3,39 & 0,068 & & 1 & 13,06 & 0,000 & $* * *$ \\
\hline sex:acantho & 1 & 4,40 & 0,039 & $*$ & 1 & 10,92 & 0,001 & $* *$ & 1 & 2,48 & 0,119 & \\
\hline expo:acantho & 1 & 0,16 & 0,690 & & 1 & 4,31 & 0,041 & $*$ & 1 & 3,76 & 0,055 & \\
\hline micro:acantho & 1 & 4,07 & 0,046 & $*$ & 1 & 2,38 & 0,126 & & 1 & 0,58 & 0,448 & \\
\hline sex:expo:micro & 1 & 8,56 & 0,004 & $* *$ & 1 & 0,00 & 0,987 & & 1 & 0,03 & 0,855 & \\
\hline sex:expo:acantho & 1 & 1,47 & 0,228 & & 1 & 0,35 & 0,556 & & 1 & 0,79 & 0,376 & \\
\hline sex:micro:acantho & 1 & 1,21 & 0,273 & & 1 & 0,24 & 0,624 & & 1 & 1,19 & 0,277 & \\
\hline expo:micro:acantho & 1 & 0,15 & 0,699 & & 1 & 0,41 & 0,523 & & 1 & 2,28 & 0,134 & \\
\hline sex:expo:micro:acantho & 1 & 0,62 & 0,434 & & 1 & 5,28 & 0,024 & $*$ & 1 & 0,48 & 0,489 & \\
\hline
\end{tabular}




\section{Figure 1 (on next page)}

Water concentrations

Water concentrations of cadmium in control and exposure tanks over time. $n=3$. 


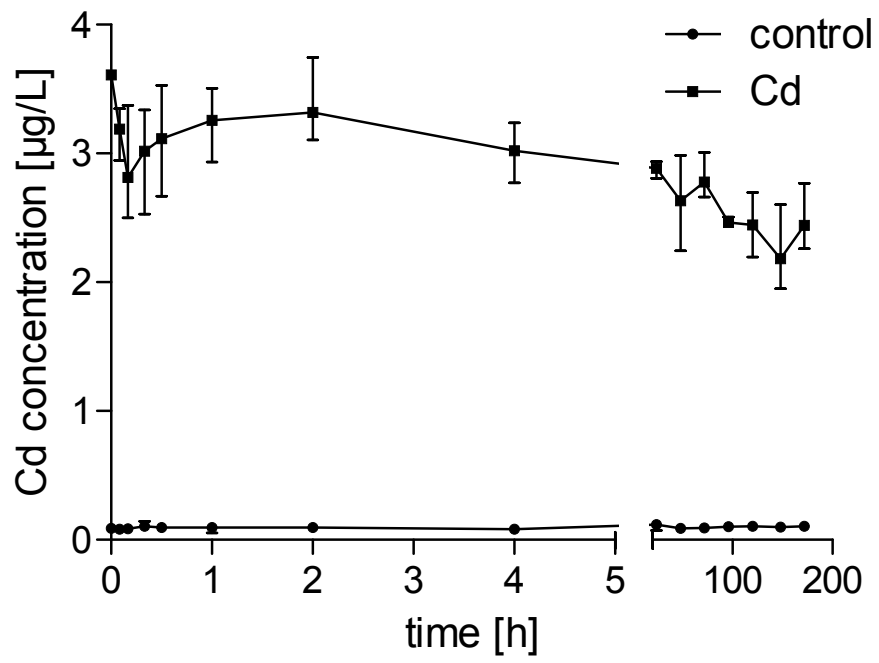


Figure 2 (on next page)

Cadmium concentrations in tissues

Cadmium concentrations in pools of $P$. minutus infected and uninfected $G$. fossarum $(n=2)$ and $P$. minutus cystacanths $(\mathrm{n}=1)$. 


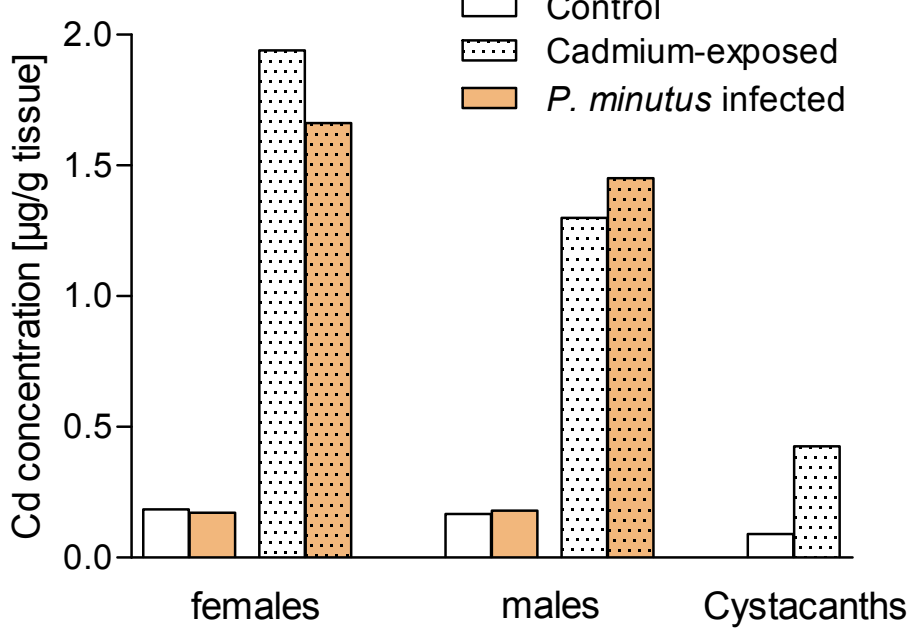




\section{Figure 3 (on next page)}

\section{Gammarid weight}

Box plot of gammarid weight depending on infection and sex. Numbers below boxes show number of gammarids. Asterisks indicate significant differences. 


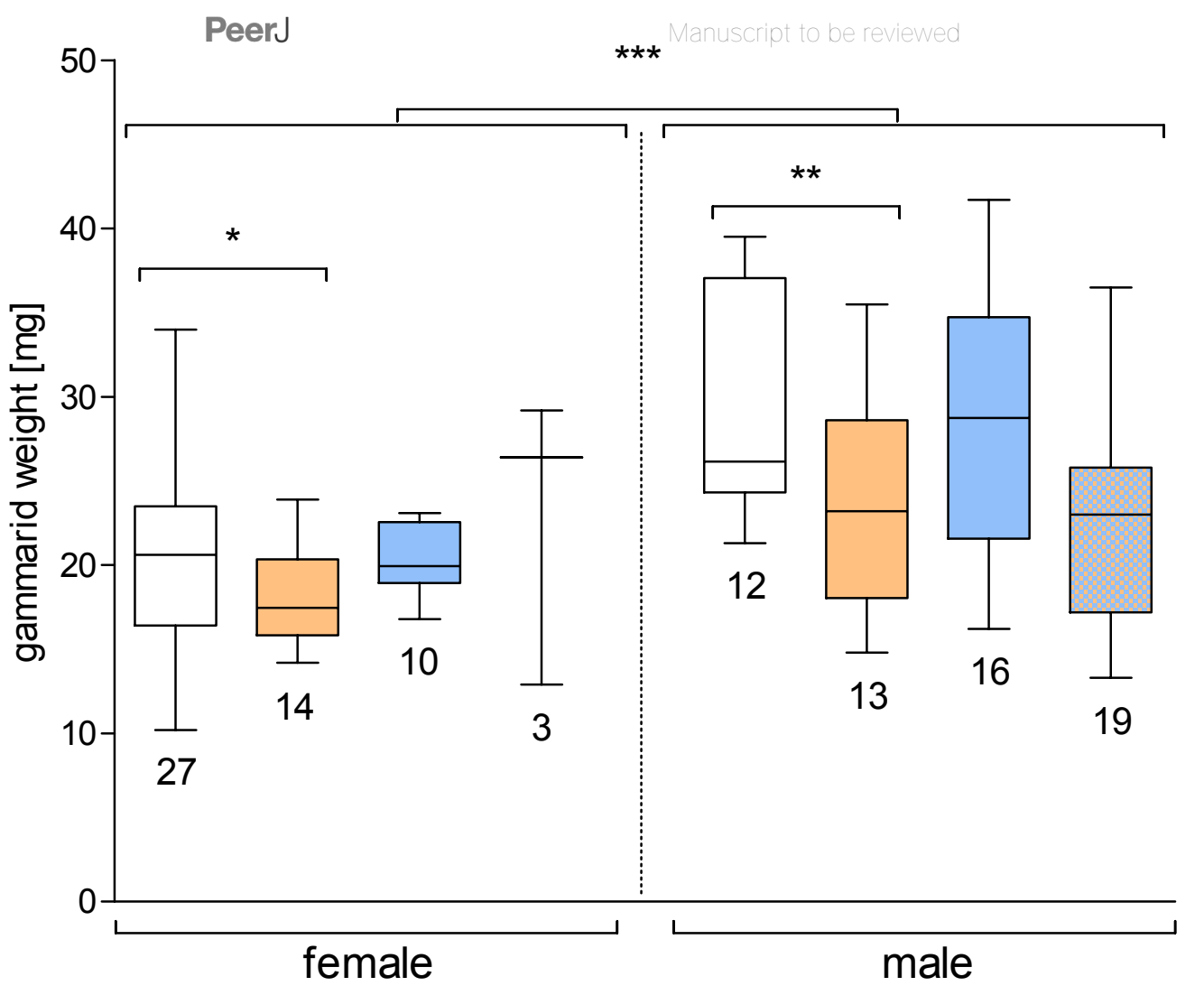

$\square$ uninfected

$\square$ D. duebenum

$\square$ P. minutus

$\square$ P. minutus $+D$. duebenum 


\section{Figure 4 (on next page)}

\section{Mortality rate of $G$. fossarum}

Mortality rate of $G$. fossarum in the test groups $(n=6)$. No significant differences between the groups were detected. Numbers above bars indicate number of gammarids. 
$\square$ uninfected

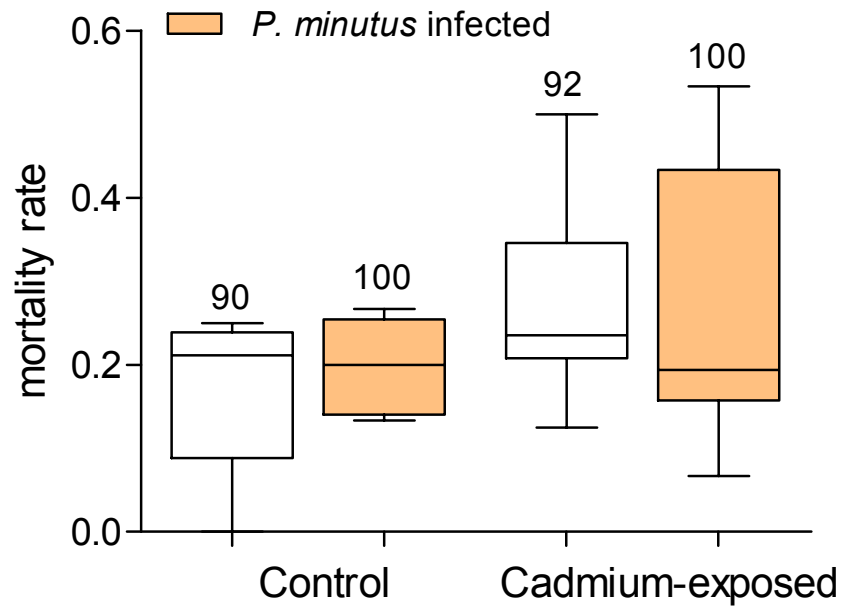


Figure $\mathbf{5}$ (on next page)

Glycogen content

Glycogen content in infected and uninfected $G$. fossarum females and males after cadmium exposure. Numbers below boxes show number of gammarids. For significant differences see table 4. 


\section{Figure 6 (on next page)}

\section{Lipid content}

Lipid content in infected and uninfected $G$. fossarum females and males after cadmium exposure. Numbers below boxes show number of gammarids. For significant differences see table 4. 
Figure 7 (on next page)

Relative hsp70 content

Relative hsp70 content in infected and uninfected G. fossarum females and males after cadmium exposure. Numbers below boxes show number of gammarids. For significant differences see table 4. 
